\title{
Appalachı̈län
}

B O O N E, N O R T H C A R O L I A

\section{Managing the Cost of Emissions for Durable, Carbon-Containing Products}

By: Gregg Marland, Eric Marland, Kevin Shirley \& Jenna Cantrell

\begin{abstract}
We recognize that carbon-containing products do not decay and release $\mathrm{CO} 2$ to the atmosphere instantaneously, but release that carbon over extended periods of time. For an initial production of a stock of carbon-containing product, we can treat the release as a probability distribution covering the time over which that release occurs. The probability distribution that models the carbon release predicts the amount of carbon that is released as a function of time. The use of a probability distribution in accounting for the release of carbon to the atmosphere realizes a fundamental shift from the idea that all carbon-containing products contribute to a single pool that decays in proportion to the size of the stock. Viewing the release of carbon as a continuous probabilistic process introduces some theoretical opportunities not available in the former paradigm by taking advantage of other fields where the use of probability distributions has been prevalent for many decades. In particular, theories developed in the life insurance industry can guide the development of pricing and payment structures for dealing with the costs associated with the oxidation and release of carbon. These costs can arise from a number of proposed policies (cap and trade, carbon tax, social cost of carbon, etc), but in the end they all result in there being a cost to releasing carbon to the atmosphere. If there is a cost to the emitter for $\mathrm{CO} 2$ emissions, payment for that cost will depend on both when the emissions actually occur and how payment is made. Here we outline some of the pricing and payment structures that are possible which result from analogous theories in the life insurance industry. This development not only provides useful constructs for valuing sequestered carbon, but highlights additional motivations for employing a probability distribution approach to unify accounting methodologies for stocks of carbon containing products.
\end{abstract}

Gregg Marland, Eric Marland, Kevin Shirley \& Jenna Cantrell (2011) "Managing the Cost of Emissions for Durable, Carbon-Containing Products Mitigation and Adaptation Strategies for Global Change Volume 16 Issue 3 pp. 325-346 Version of Record Available from (www.springer.com) 


\section{Introduction}

There are now several motivations for an accurate description of the human portion of the global carbon cycle, that is, an accurate accounting of emissions and sinks of carbon caused by human actions. It is important to understand the natural portion of the global carbon cycle and to be able to understand and predict the impact of human activities on the climate system. We need to be able to manage the human impact on the carbon cycle and to be able to monitor and verify compliance with national or international commitments. To do this, we need to be able to measure, analyze, and understand human-driven emissions and sinks of carbon. In addition, if we are interested, for example, in independent monitoring and verification of emissions with atmospheric or satellite measurements (see, for example, National Research Council 2010), or if there is some cost imposed on emissions, it will be important to establish as accurately as reasonably possible the correct quantity and time of emissions. Whether the cost of emissions is simply recognition of the cost of emissions to society as a whole (the social cost of carbon, for example, FAWG 2010), or whether there is a carbon tax or cap and trade limitation on emissions (see Stern 2007), the costs imposed on the emitter could be significantly different if we can correctly characterize the time of emission rather than assuming that the emissions occur at the time of product "consumption" or that emissions estimates can be based on some simple assumption such as exponential decay of durable products. Here we are not concerned with the value that is placed on emitted carbon or the method used to calculate that cost; only that there is such a cost and that it can be determined.

When fossil fuels are combusted or biomass is burned, the carbon is released to the air as carbon dioxide. When coal, oil, natural gas, or biomass harvests are used for durable products like asphalt, lubricants, waxes, paper, or construction lumber we can recognize that it has been "consumed" or perhaps acknowledge that it has been "exposed to the hazard of oxidation to $\mathrm{CO}_{2}$," but it is still important to obtain the best possible understanding of when the carbon is actually released to the atmosphere as carbon dioxide. While fuel products typically release their stored carbon into the atmosphere relatively soon after production, there are many carbon containing products that do not oxidize for much longer.

A common assumption is that oxidation of long-lived carbon containing products can be adequately described by simple exponential decay. An earlier paper (Marland and Marland 2003) has discussed an alternative approach for treating the lifetime of durable, carbon-containing products. The paper indicated some preliminary financial implications for emitters if the life time of wood products is not adequately considered. It also was shown that these products should be differentiated by their age. That is, the probability that a particular product oxidizes depends not only on how large the stock is, but also on when the stock was produced. For example, a 
50 year-old house made of wood is more likely to be taken out of service than a five year-old house. The age of the product matters.

It is this difference in probability according to the time since production that was first brought up as the distributed decay model by Marland and Marland (2003) and outlined in detail in Marland et al. (2010). In the distributed decay model, a probability distribution is used to determine how much of a particular year's production decays, or is released, in any time interval.

It was further shown in Marland et al. (2010), that because of the distributed nature of the oxidation of the carbon in these long lived carbon containing products, there were significant implications on the economics of any carbon market that might arise. In particular, the present value of carbon that oxidizes some time in the future gives rise to large differences from previous models of stock accounting. This present value can be estimated with only moderate data on the time course of oxidation from different products.

In two earlier papers (Marland and Marland 2003; Marland et al. 2010) the extensive earlier literature on the treatment of durable wood products in $\mathrm{CO}_{2}$ emissions inventories has been summarized and this review is not repeated here. These earlier discussions range from the initial IPCC (IPCC 1997) suggestion of a default assumption that the stock of wood products is not changing and can be ignored; to other papers emphasizing the magnitude of the annual change in wood stocks and their importance for some countries (see, for example, Pingoud et al. 2003). There has been considerable discussion of who should be responsible for emissions from durable wood products, the producer or the current holder of the products, and this discussion too is summarized in Marland et al. (2010). The most recent version of the Intergovernmental Panel on Climate Change (IPCC 2007) guidelines for national greenhouse gas emissions inventories focuses on the first order decay of products from a single pool but recognizes that other approaches are possible.

In the present paper, we work to outline more fully the economic implications of moving to a distributed approach for the oxidation of durable products. Although the debate on how costs, credits, and prices are allocated is ongoing, we assume in a simple manner that there is some cost associated with the release of $\mathrm{CO}_{2}$ to the atmosphere and that there is a need to keep an account of those costs and how they are distributed. The prevailing discussion currently focuses on a cap and trade limitation in which emissions above some limit would incur either financial penalties or the need to purchase emissions permits in the market. Since emissions from a single source (a product that has been produced, a land use change, etc) are spread out over time, the cost of emissions from that source can be discounted over time and a present value calculated. In addition, the cost per unit of carbon emitted may change over time and must be properly taken into account.

We also assume that sequestration activities refer specifically to removal of carbon from the atmosphere and not bundling of carbon already contained in the terrestrial environment. This assumption leads to the basic premise that emissions directly contribute to increases of carbon in the atmosphere while sequestration directly contributes to decreases of carbon in the atmosphere. Any indirect affects are assumed to act only through emissions or sequestration.

Here we focus on the present value calculations of various sources of emissions and the potential trade in the value of those emissions. We briefly touch on 
sequestration activities, but leave that until the discussion. Because we think of emissions from any source as being distributed over time, we are able to pull theoretical results from other fields where similar costs are incurred in a distributed way over time. In particular, we make use of theory developed in the life insurance industry to guide our development of ideas related to potential interactions in a market for carbon emissions based on the concept that probability distributions describe the oxidation of carbon containing products, regardless of the source of that carbon.

We base our model development on theoretical results from actuarial science, and illustrate the strong analogy between accounting for the costs of emissions and accounting for the costs of life insurance to show how that theory has guided our models.

The objective of this paper is to establish an analogy between purchasing insurance on human lives and paying for the loss of carbon from durable, carboncontaining products. Establishing this analogy allows us to take advantage of the considerable experience of the life insurance industry in developing a model for treating carbon-containing products. It also helps us to understand the importance of adopting an appropriate and accurate model for the oxidation of durable products. Section 2 of this paper develops the analogy and Sections 3-5 use the analogy to develop the mathematics of establishing the value of carbon emissions and the possibilities for paying for delayed emissions. Sections $6-8$ of the paper continue the mathematical development to show the treatment of products that are produced year after year, the termination or secondary trading of contracts, and the consideration of error. In Section 9 we return to a non-mathematical discussion of the implications and importance of the analogy and the mathematical development. It is our intent that the nature, purpose, and importance of the paper be apparent to the nonmathematical reader by reading only Sections 2 and 9 .

\section{Developing the analogy}

As a single ton of carbon sits in the ground as a fossil fuel or in a living tree, that carbon is harnessed to the earth and will not be oxidized into the atmosphere. Perhaps the carbon is even accumulating as a tree by pulling carbon out of the atmosphere. As soon as that carbon is harvested for producing a product, that ton of carbon then has the potential to be released into the atmosphere as $\mathrm{CO}_{2}$ through some probability distribution. This ton of carbon will live a useful life as, perhaps, a utility pole for a power company. In the end though, the utility pole will be removed from service and the carbon will either be released, refashioned into another product, or placed in a landfill. The goal here is to keep track of the carbon in the utility pole and, if we assume that some portion is ultimately released, account for its release to the atmosphere.

If we are to put a price tag on the release of this carbon to the atmosphere, we will want to know how much that release might cost, depending on when that release occurs and how we choose to pay for it. It is likely that the cost will increase over time. Although any increase will be unlikely to follow a nice predictable pattern, we will assume for this paper that the functional form of that increase is relatively simple. We recognize that the cost must include both economic and ecological components, 
incremental and catastrophic, but here we only assume that such a valuation exists and base our calculations on some simple assumptions on how that value might change.

This cost of carbon emissions rests on the shoulders of society and might be paid by way of a variety of adaptation or mitigation strategies implemented at the regional or national level. While this burden is ultimately passed on to individuals, it is clearly the responsibility of climate change treaty signers to administrate any regulations that are put in place and to organize efforts to ameliorate the incurred costs.

This structure can be put into a diagram that follows the "money trail" (Fig. 1). The emitter pays the cost of emissions as it causes the release of carbon to the atmosphere. This payment is made to a party that is able to invest those monies into efforts to compensate society for the costs of the release, either through adaptation strategies or mitigation of the effects of the release. The composition of such an agency is not presently clear, but it could fall on the governments who sign future climate treaties to make efforts to pool resources to deal with climate change. Monies could be used mitigate additional emissions or could be distributed to aid those most in need of adaptation strategies, those most impacted by change, or however international agreements dictated.

It is this structure and potential pricing arrangement that we find analogous to the life insurance industry (Fig. 2). Keep in mind that just as the carbon from a particular activity is released in a distributed way, the expected lifetimes of people are distributed through time. The life insurance industry cannot function for an individual and relies on large groups of people to realize the predictability of the distribution of expected lifetimes. In other words, we do not look at individuals and their life insurance, but at large groups who contract with life insurance companies.

So a group of people want to invest money so that when they die, their beneficiaries are not found wanting. The insurance company, taking a management fee, acts as an intermediary to hold and invest the money so that it is available when it is needed. The large size of the group makes it possible to project the amount of money needed in order to pay the beneficiaries when the time comes.

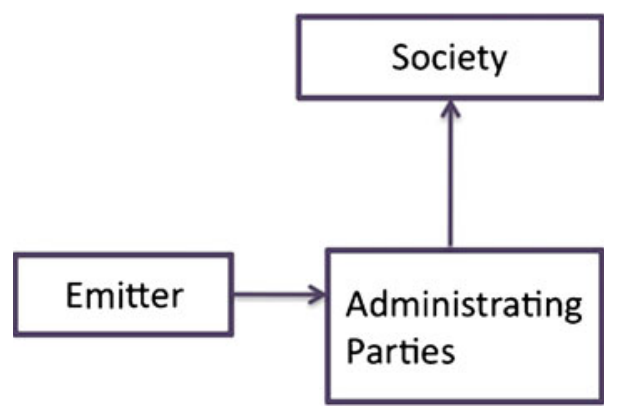

Fig. 1 The cost of carbon emissions An emitter is required to save money in such a way that when carbon is released from an activity for which it is responsible, society receives some compensation for the costs incurred as a consequence of that release. The administrators of the carbon agreements act as intermediaries: collecting the money, investing the money as best they can, and coordinating or administrating adaptation and mitigation strategies to compensate for that release 


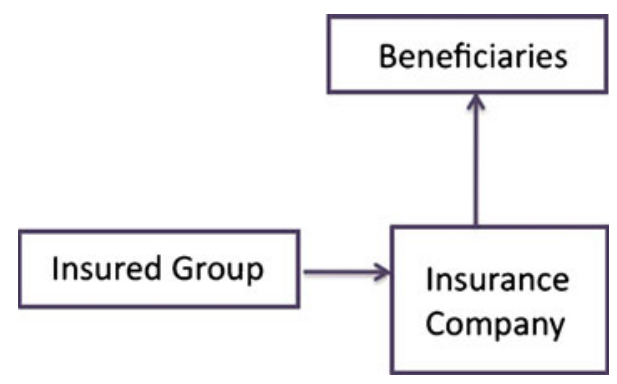

Fig. 2 The cost of life insurance A group desires to save money in such a way that when a member of the group dies, the beneficiaries of that member receive some compensation for their loss. The insurance company acts as an intermediary: collecting the money, investing the money as best it can, and administering the compensations when necessary

The group wants to invest money to compensate their heirs for their potentially untimely deaths. This is analogous to the emitter who wants (is required) to invest money to compensate society for the cost of releasing carbon to the atmosphere. The insurance company and the administrating parties act to pool the various funds in order to pay the costs as they occur.

Just as the beneficiaries prefer that the insured lives a bit longer, society hopes that the release of carbon might be delayed, and so deferring the costs that ultimately, and perhaps inevitably, result. The insurance company and the administrating parties also prefer that the costs are delayed since that delays payment of the costs (and increases profits).

With this analogy established, we resist the urge for morbid comparisons but look toward what advantage we might gain from the possible link. What we find is that while the concepts of the cost and paying for the release of carbon to the atmosphere are relatively new, the life insurance industry has been around a bit longer. In fact the life insurance industry has been creating, modifying, and fine tuning theories for decades. These are well-established ideas that work. Using some of these already tried and tested ideas as a starting point can reduce the time needed for development and experimentation. In order to take full advantage, we continue to lean on our analogy.

The expected lifetime of a person depends on many factors. Does the person participate in high risk activities such as fighting fires or sky diving? Does the person lead a healthy lifestyle and maintain a healthy weight? What health risks are present based on the person's location? The expected lifetimes can be predicted, with some error, from life tables developed by the industry.

Carbon from the same source might be released very differently depending on its use, whether it be to shore up a mine, to burn in a fireplace for heat, or to sit on in the form of a comfortable office chair. The location of a product such as a utility pole might result in differences in the salinity, humidity, or pest exposure. The probability distributions for the release of that carbon would look very different. The expected lifetimes of these products can be predicted with some error by researchers requested perhaps by an international body such as the UN Framework Convention on Climate Change. 
There are many different types of life insurance. You might want to pay for the entire policy up front because you happen to have the money available. You might prefer to pay monthly installments. You might want a fixed payment or one that is low now but may increase later. You might end up with supplemental policies or need to change policies when you take on a riskier career path.

You might choose to pay for the release of the carbon when you first cut down the tree or you might wish to spread out the payments over a number of years. You might find that you pay all of the cost of that carbon to a single party or you might need to pay a fraction of the cost to several parties, perhaps spread over a number of different years. You might want to pay one party for some period of time and switch to another at a later date. You might recycle the product into another product that has a different probability distribution for its release.

We see here a close parallel between the costs and benefits of life insurance and the costs and release of carbon in a carbon market. In the following sections, we will draw upon this analogy and the vast theoretical history of the insurance industry to outline the possible avenues we might take in developing a market for the release of carbon into the atmosphere.

In the calculations that follow, we consider a sample price of $\$ 50$ per ton of $\mathrm{CO}_{2}$ released. All values of carbon are then accounted by their ton of $\mathrm{CO}_{2}$ potential. That is, $1 \mathrm{t}$ of " $\mathrm{CO}_{2}$ potential" is the quantity of carbon that produces $1 \mathrm{t}$ of $\mathrm{CO}_{2}$. This somewhat eases the burden of continually converting between tons of carbon in products and tons of $\mathrm{CO}_{2}$ in the atmosphere.

\section{The value of oxidizing carbon}

Although subtle differences require us to re-derive each formula, we will be referring to different life insurance models (see for example, Bowers et al. 1997) and drawing on this analogy in the remainder of the paper. For this reason and for future reference, we describe some basic life insurance models for whole life insurance purchased for a newborn. Then we will build off of that model and describe life insurance for an insured of any age at the time of purchase. When it makes sense, we will introduce standard actuarial notation. For example, we will reference the person purchasing insurance at exact age $x$ using the notation $(x)$. Also, a bar may appear over a variable or result if it is a continuous variable or a result derived from a continuous variable. Where possible we replace actuarial notation with more standard mathematical notation.

In actuarial mathematics, one first defines the age at death random variable, $X$, giving the age at which a newborn dies. The density function $f_{X}$, gives the density of mortality for the newborn or entity (0). Therefore, the probability of (0) dying within $n$ years is the cumulative distribution function, $\int_{0}^{n} f_{X}(t) d t$. If $\$ 1$ of life insurance is to be paid at the instant of death of (0), then to determine an expected cost, the present value of the $\$ 1$ benefit variable is defined,

$$
\bar{Z}=e^{-\delta X},
$$

where $\delta$ is the annualized force of interest used for discounting.

The discount rate used in discounting the future death claims back to the present is a long term discount rate and usually related to economic conditions and the return 
on assets backing the policy. Therefore, the expected present value of the $\$ 1$ benefit payment is just the expected value of the random variable $\bar{Z}$, given by

$$
\bar{A}=E[\bar{Z}]=\int_{0}^{\infty} e^{-\delta t} f_{X}(t) d t .
$$

$\bar{A}$ is referred to as the net single premium (Bowers et al. 1997, pp. 95-96), as it represents the expected cost of the benefit paid at the moment of death, net of any expenses or profit. For a face amount of $F$, the net single premium is $F \bar{A}$. It is also worth noting that for a benefit amount of $\$ 1$, and $K$ newborns the net single premium is

$$
\sum E[\bar{Z}]=K \bar{A} \text {. }
$$

More relevant to our application, it may be the case that the benefit varies in time. In that case the present value random variable is

$$
\bar{Z}_{b(\cdot)}=b_{X} e^{-\delta X},
$$

where $b_{X}$ is the benefit if death occurs at age $X$. In this case, the net single premium is $E\left[\bar{Z}_{b(\cdot)}\right]$, where the expected value is calculated with respect to the age at death probability density function (pdf) as described above. A description of varying benefit life insurance models can be found in Bowers et al. (1997, pp. 105-108). The models for the net single premium just described are referred to as "instant of death" or "continuous" whole life models since the death claim is assumed to be paid at the instant of death and the contract is for the entire lifetime of the insured, that is, the claim is certain to be paid since death is certain and it is just a matter of when that death occurs.

Having described the basic net single premium whole life model for (0), we parallel its development with a model for wood decay. For 1 unit of wood stock first exposed to a decay hazard at exact time 0 , death will mean "decay" or "oxidation". We will use the random variable $T$ to denote the time of oxidation. Consistent with Marland et al. (2010) we denote the density of $T$ by $P(T)$. Therefore the amount of $\mathrm{CO}_{2}$ released at time $T$ due to oxidation is itself a random variable that is a function of the variable $T, \mathrm{CO}_{2}(T)$.

For the present we take $\mathrm{CO}_{2}(T)$ to be proportional to the amount of wood decay at time $T$ and the constant of proportionality set to 1 . Let $b_{T}$ denote the random variable representing the cost per unit of emitted $\mathrm{CO}_{2}$ in year $T$. For example, if the initial cost of a unit of emitted $\mathrm{CO}_{2}$ is $b$, then $b_{T}=b e^{r T}$ assumes a continuous inflation rate of $100 r \%$ annually in the cost of emitted $\mathrm{CO}_{2}$ or an effective annual rate of inflation of $e^{r}-1$. Other models for the projected cost of emitted $\mathrm{CO}_{2}$ may be used and developed as the market develops, but $b_{T}$ seems to be a reasonable initial form for projecting the unit cost of $\mathrm{CO}_{2}$. Then the present value of the cost per unit of emitted $\mathrm{CO}_{2}$ in year $T$ is

$$
\bar{Z}_{b}=b_{T} e^{-\delta T}
$$

where $\delta$ is the assumed long term annual force of interest used for discounting. Therefore, the expected present value of the cost of one unit of emitted $\mathrm{CO}_{2}$ is

$$
\bar{C}=E\left[b_{T} e^{-\delta T}\right]=E\left[b e^{(r-\delta) T}\right]=\int_{0}^{\infty} b e^{(r-\delta) t} P(t) d t
$$


which is analogous to the variable benefit whole life model previously discussed.

Finally, in a wood stock, there are many units of wood and hence many units of $\mathrm{CO}_{2}$ sequestered. To be consistent with notation in Marland et al. (2010), let $J(t)$ represent the production at time $t$, and assume for now that $J(t)=J(0)$, i.e. all of the production takes place at time 0 . Then the total expected present value of the cost of this single cohort of wood stock is $J(0) \bar{C}$. The cost determination when $J(t)$ is continuous over time is discussed in the section on continued production. The infinite limit should not be misconstrued as an obstacle to applying this model in a practical manner. The present value of the cost of the $\mathrm{CO}_{2}$ sequestered in time as given by the right tail of the distribution (upper 1\%) is small relative to the cost of the $\mathrm{CO}_{2}$ emitted earlier. A fee could be charged up front to account for the tail cost, providing for a practical maturity date of the cost. Numerical methods in today's mathematical software readily handle the infinte limit for calculation purposes.

Example 1 To calculate the net single cost for $1 \mathrm{t}$ of waste, bark, and fuel. The distribution for oxidation is described in Table 1 of Marland et al. (2010) is a gamma distribution with paramters $k=1.305$ and $\theta=4.918, P(t)=\operatorname{Gamma}(t)$. If we assume the initial cost of $\mathrm{CO}_{2}$ is $\$ 50$ per ton, an inflation rate of $2 \%$, and a long term interest rate for discounting of $5 \%$.

$$
\bar{C}=50 \int_{0}^{\infty} e^{-0.03 t} \operatorname{Gamma}(t) d t=41.78
$$

\section{Payment plans}

The entity providing the funding may wish to spread the payment over $n$ years. This is accomplished by solving for the level payment, $P$, in the equation below:

$$
P \bar{a}_{\bar{n} \mid}=J(0) \bar{C}
$$

where $\bar{a}_{\bar{n} \mid}$ is the present value of an annuity of $\$ 1$ for continuous payments for a term of $n$-years. To calculate a premium, it is typical in actuarial applications to use the same discount factor for the annuity on the left side of the equation as used in calculating $\bar{C}$ on the right side of the equation. Notice that $P$ is a level payment and for practical considerations the continuous annuity can be modified to be a discrete annuity reflecting any payment period desired. The equation above illustrates the actuarial payment principle that the present value of payments is equal to the present value of costs.

For a practical example, suppose the agreed upon funding is for a five year level payment, paid annually at the beginning of each year, then $P \ddot{a}_{\overline{5}}=J(0) \bar{C}$ and therefore

$$
P=\frac{J(0) \bar{C}}{\ddot{a}_{\overline{5}}}
$$

where $\ddot{a}_{\overline{5} \mid}$ is the present value of $\$ 1$ paid at the beginning of each year for five years; In financial terms $\ddot{a}_{\overline{5} \mid}$ is a five year annuity due. If this were life insurance, then the annuity would be an expected value due to the fact that if an insured dies, no more premium payments will be paid, which is not the case above as the annuity in our case is discounted only for interest. Since we are measuring cost at the instant of oxidation 
Table 1 Illustrates funding of the cost of $\mathrm{CO}_{2}$ over $1,5,10$, and 15 years where it is assumed the production is $J(0)=1$ tons $\mathrm{CO}_{2}$ waste, bark, and fuel

\begin{tabular}{lcc}
\hline $\begin{array}{l}\text { Years to } \\
\text { pay (k) }\end{array}$ & $\begin{array}{l}\text { k-Year annuity } \\
\text { due } \ddot{a}_{\bar{k} \mid}\end{array}$ & $\begin{array}{l}\text { Payment } \\
(\$)\end{array}$ \\
\hline 1 & 1 & 41.78 \\
5 & 4.5355 & 9.21 \\
10 & 8.0678 & 5.18 \\
15 & 10.8187 & 3.86 \\
\hline
\end{tabular}

and the payments are assumed to be made at discrete moments in time, this model is said to be of the semi-continuous type.

Example 2 We calculated the net single cost $\bar{C}$ for $1 \mathrm{t}$ of waste, bark, and fuel in Example 1. Table 1 illustrates the payment for this net cost using various payment terms. To calculate the payment for a plan requiring five payments at the beginning of each year we use the discount factor $e^{-0.05 t}$ for the annuity where

$$
\ddot{a}_{\overline{5 \mid}}=\sum_{k=0}^{4} e^{-0.05 k}=4.5355 .
$$

Hence $\bar{C} / \ddot{a}_{\overline{5 \mid}}=41.78 / 4.5355=9.2118$ per ton. Notice that one effect of discounting is that paying the full amount up front costs less than spreading the payments over several years.

\section{Contract possibilities}

Given a distribution for the oxidation of the product, the amount of product exposed to the oxidation hazard, an assumption about the long term price of $\mathrm{CO}_{2}$, and a long term interest rate assumption used for discounting, a net cost can be calculated as shown above. Drawing upon the life insurance analogy allows access to well known life insurance models which can be used to overcome some of the restrictions and deficiencies in the net single cost model.

In particular, to mitigate the importance of the long term discount rate and a long term assumption on the price inflation of emitted $\mathrm{CO}_{2}$, a shorter term, term insurance model may be more appropriate. Or, to overcome the restriction of only using a single contract for a single stock exposed to oxidation, contracts covering future periods of a stock's oxidation can be used. These later contracts will be referred to as deferred cost contracts and are analogous to deferred life insurance. We can use term and deferred cost contracts in the event that the product is exposed to one source of oxidation for a certain time and then to a different source of oxidation with a different distribution at some point in the future. The deferred model may be especially useful if the change in the oxidation distribution is known in advance.

\subsection{Short term contracts}

In an $n$-year renewable term model the assumptions may be short term and revisited at the end of the $n$-year term. The main point of this model would be to shorten the horizon of the model to allow for renegotiation and a revisiting of the assumptions after a relatively short time. This may be particularly valuable early in carbon 
contracts when actuarial data are lacking and costs are still being defined. A oneyear term model may be viewed as a pay-as-oxidation occurs model. This model also allows for more frequent trading of the carbon sequestered in certain stocks.

Analogous to life insurance, we define the present value variable for the n-year term payment of $\$ 1$ if the decay of one unit occurs within $n$-years.

$$
\bar{Z}_{n}=\left\{\begin{array}{cl}
e^{-\delta T} & , 0 \leq T \leq n \\
0 & , T>n
\end{array}\right\}
$$

Therefore, the expected cost over the initial term period beginning at time $t=0$ for a unit of sequestered $\mathrm{CO}_{2}$ is given by

$$
\bar{C}_{0: n}=E\left[b_{T} \bar{Z}_{n}\right]=\int_{0}^{n} b_{t} e^{-\delta t} P(t) d t
$$

where $b_{t}$ is the cost per unit at time $t$. The cost for $\mathrm{CO}_{2}$ emissions beyond the term period will only be considered at the time of renegotiation. Just as in the models above, the funding can be a single pay or paid over any number of years up to $n$-years. The mathematics to determine the expected cost after the initial term needs to be conditional on the elapsed time since the entity has been exposed to the hazard which naturally leads to a conditional distribution called the future lifetime distribution.

In order to define the future lifetime random variable, $T(x)$, given the future lifetime of $(x)$, we first define the conditional probability density function for the stock having been exposed to the oxidation hazard at time 0 and survived for $x$-years:

$$
f_{T(x)}(t)=\frac{P(x+t)}{\int_{x}^{\infty} P(t) d t} .
$$

The interpretation of the cumulative distribution function, $\int_{0}^{n} f_{T(x)}(t) d t$ is the expected percentage of this stock to oxidize within the next $n$ years. Notice that $T(0)$ is then the age at death random variable, $T$, defined earlier. Similar to what was done above, we define the present value of the cost random variable for an $n$-year term for the stock that has survived the oxidation hazard to age $x$ (Bowers et al. 1997, p. 95):

$$
\bar{Z}_{x: n}=\left\{\begin{array}{cl}
e^{-\delta T} & , 0 \leq T(x) \leq n \\
0 & , T(x)>n
\end{array}\right.
$$

It is possible that $x$-years after the initial contract market conditions will have changed. A new $\mathrm{CO}_{2}$ cost per unit function for the surviving stock, $b_{x, T(x)}$, may be appropriate or otherwise renegotiated, as well as a different discount rate, $\delta_{x}$. Hence the expected present value for the cost over the next $n$-years can be found

$$
\bar{C}_{x: n}=\int_{0}^{n} b_{x, t} e^{-\delta_{x} t} f_{T}(t) d t
$$

Using this cost, a method of funding can be chosen, that is, single pay, $n$-year level pay, etc. This process can continue for $x=0, n, 2 n, 3 n, \ldots$ indefinitely until such time that the amount of original stock, $J(0)$, left is de minimis. Of course the terms do not 
have to be of the same length. After any term is reached, the expected percentage of stock left at time $t=l$ from the original stock $J(0)$ is

$$
J(0)-J(0) \int_{0}^{l} f_{T}(t) d t .
$$

At time $l$, Eq. 5 can be applied with $x=l$ and $n$ being any desired term.

It is interesting and informative to note that the net single premium for a whole life contract can be written as a sum of discounted net single premiums for term insurances which use the same assumptions and discount rate as the whole life model. For example, see Cunningham et al. (2008, p. 149). We use this analogy to rewrite $\bar{C}$ in a form of 1-year term costs for $\mathrm{CO}_{2}$ where the same discount rate, and cost of $\mathrm{CO}_{2}$ function are used for all term calculations. The mathematical demonstration of decomposing $\bar{C}$ into one-year term costs follows.

$$
\begin{aligned}
\bar{C} & =\int_{0}^{\infty} e^{(r-\delta) t} P(t) d t \\
& =\sum_{k=0}^{\infty} \int_{k}^{k+1} b e^{(r-\delta) t} P(t) d t \\
& =\sum_{k=0}^{\infty} b e^{r k} e^{-\delta k} \int_{k}^{k+1} e^{(r-\delta)(t-k)} P(t) d t \\
& =\sum_{k=0}^{\infty} b e^{r k} e^{-\delta k} \int_{k}^{\infty} P(t) d t \int_{k}^{k+1} e^{(r-\delta)(t-k)} \frac{P(t)}{\int_{k}^{\infty} P(t) d t} d t \\
& =\sum_{k=0}^{\infty} e^{-\delta k} \int_{k}^{\infty} P(t) d t \int_{0}^{1}\left[b e^{r k}\right] e^{(r-\delta)(\tau)} \frac{P(\tau+k)}{\int_{k}^{\infty} P(t) d t} d \tau \\
& =\sum_{k=0}^{\infty} e^{-\delta k} \int_{k}^{\infty} P(t) d t \bar{C}_{k: 1}
\end{aligned}
$$

For the $k$ th-term $e^{-\delta k}$ is the discount factor discounting back to time $t=0$, $\int_{k}^{\infty} P(t) d t$ is the expected percentage of stock left undecayed at time $t=k,\left[b e^{r k}\right]$ is the price of one unit of $\mathrm{CO}_{2}$ at time $t=k$, and $\bar{C}_{k: 1}$ is the one year term cost per ton of $\mathrm{CO}_{2}$ emitted during the time interval $t=k$ to $t=k+1$ (year $\left.k+1\right)$ from the stock that has been exposed to the decay hazard for $k$-years and survived. Therefore, if $1 \mathrm{t}$ of $\mathrm{CO}_{2}$ is sequestered in a stock at time zero, then $\int_{k}^{\infty} P(t) d t \bar{C}_{k: 1}$ is the cost of the emissions in year $k+1$ from that stock.

Example 3 Table 2 illustrates one-year term costs for three different wood products of widely varying mean life expectancy. We show the calculation for the one year term cost for waste, bark, and fuel, for the third year. In general, the cost of emissions per ton in year $k+1$ is given by $\int_{k}^{\infty} P(t) d t \bar{C}_{k: 1}$. For waste, bark, and fuel

$$
\int_{2}^{\infty} P(t) d t=1-\int_{0}^{2} \operatorname{Gamma}(t) d t=0.7889
$$


Table 2 Illustrates one-year term costs compared for different products

\begin{tabular}{lccc}
\hline Year & Waste, bark, fuel $(\$)$ & Pulpwood $(\$)$ & Fencing $(\$)$ \\
\hline 1 & 4.69 & 19.08 & $4.0 \times 10^{-8}$ \\
2 & 5.81 & 14.95 & $3.6 \times 10^{-6}$ \\
3 & 5.68 & 8.28 & $4.6 \times 10^{-5}$ \\
4 & 5.25 & 4.23 & $2.5 \times 10^{-4}$ \\
5 & 4.72 & 2.08 & $9.0 \times 10^{-4}$ \\
PV total cost & 23.74 & 46.15 & $1.0 \times 10^{-3}$ \\
Five-year term & 23.74 & 46.15 & $1.0 \times 10^{-3}$ \\
\hline
\end{tabular}

Notice the five-year term cost is equal to the present value of the five one-year term costs. We assume $1 \mathrm{t}$ of production (tons $\mathrm{CO}_{2}$ potential), and the assumptions previously stated in Example 1

or $78.89 \%$ of the product has survived oxidation to the beginning of year 3 and

$$
\bar{C}_{2: 1}=\int_{0}^{1}\left[50 e^{.02 x 2}\right] e^{(-0.03) \tau} \frac{\operatorname{Gamma}(\tau+2)}{\int_{2}^{\infty} \operatorname{Gamma}(t) d t} d \tau=7.20
$$

yielding a term cost of $\$ 5.68$ per initial ton of product exposed to oxidation.

\subsection{Deferred contracts}

Rather than using the short term contracts in a pay-as-oxidation occurs model, a deferred cost model can be used to divide the contract among multiple traders. In this case long term assumptions about the price of $\mathrm{CO}_{2}$ and the discount rate will be necessary. We begin with the expected present value of the cost and write it as the sum of an n-year term cost and a whole life model for the expected amount of sequestered carbon at time $n$. Recall, the expected present value of the $n$-year term cost is denoted $\bar{C}_{0: n}$. We will denote the expected value of the cost of $\mathrm{CO}_{2}$ emitted after time $n$ as ${ }_{n} \mid \bar{C}$. Thus, using our notation

$$
\bar{C}=\bar{C}_{0: n}+{ }_{n} \mid \bar{C} .
$$

Hence $\bar{C}_{0: n}$, could be traded to one party and ${ }_{n} \mid \bar{C}$ from the same stock could be traded to a different party. The following calculation demonstrates how to accomplish this division mathematically and provides the mathematical formulation for ${ }_{n} \mid \bar{C}$.

$$
\begin{aligned}
\bar{C} & =\int_{0}^{\infty} b e^{(r-\delta) t} P(t) d t \\
& =\int_{0}^{n} b e^{(r-\delta) t} P(t) d t+\int_{n}^{\infty} b e^{(r-\delta) t} P(t) d t \\
& =\int_{0}^{n} b e^{(r-\delta) t} P(t) d t+\left[b e^{r n}\right] e^{-\delta n} \int_{n}^{\infty} e^{(r-\delta)(t-n)} P(t) d t \\
& =\int_{0}^{n} b e^{(r-\delta) t} P(t) d t+\int_{n}^{\infty} P(t) d t\left[b e^{r n}\right] e^{-\delta n} \int_{n}^{\infty} e^{(r-\delta)(t-n)} \frac{P(t)}{\int_{n}^{\infty} P(t) d t} d t \\
& =\int_{0}^{n} b e^{(r-\delta) t} P(t) d t+e^{-\delta n} \int_{n}^{\infty} P(t) d t \int_{0}^{\infty}\left[b e^{r n}\right] e^{(r-\delta)(\tau)} \frac{P(\tau+n)}{\int_{n}^{\infty} P(t) d t} d t \\
& =\bar{C}_{0: n}+e^{-\delta n} \int_{n}^{\infty} P(t) d t \bar{C}_{n: \infty}
\end{aligned}
$$


Notice for the second-term $e^{-\delta n}$ is the discount factor discounting back to time $t=0, \int_{n}^{\infty} P(t) d t$ is the expected percentage of stock left undecayed at time $t=n$, $\left[b e^{r n}\right]$ is the price of one unit of $\mathrm{CO}_{2}$ at time $t=n$, and $\bar{C}_{n: \infty}$ is the net cost for the stock that has been exposed to the decay hazard for $n$-years and survived. Therefore, we obtain

$$
{ }_{n} \mid \bar{C}=e^{-\delta n} \int_{n}^{\infty} P(t) d t \bar{C}_{n: \infty}
$$

We use the term "deferred cost method" in reference to ${ }_{n} \mid \bar{C}$ which is analogous to the expected present value of the cost of a $n$-year deferred whole life insurance policy for a newborn (Bowers et al. 1997, p. 103).

The short term and deferred cost methods present a number of possibilities for trading the cost of the $\mathrm{CO}_{2}$ emission from a single source stock. For example, the cost of the $\mathrm{CO}_{2}$ could be traded on an as-oxidized term basis for a certain number of years. At some point, the expected cost of the carbon still sequestered could then be traded either for its expected present value or using the deferred method described above.

Example 4 We show the calculation for the five year deferred cost for waste, bark, and fuel. This result is immediate since we have already calculated $\bar{C}_{0: 5}$ and $\bar{C}$ from previous examples. ${ }_{5} \mid \bar{C}=\bar{C}-\bar{C}_{0: 5}=41.78-27.7=18.04$. In Table 3 , five year term and deferred costs are compared for products with different oxidation distributions as well as the percentage of stock projected to be unoxidized at five years.

To illustrate further, suppose that a certain stock is to be divided into three contracts, each of equal value. Then $n$ and $m$ can be found so that

$$
\frac{\bar{C}}{3}=\bar{C}_{0: n}=e^{-\delta n} \int_{n}^{\infty} P(t) d t \bar{C}_{n: m}={ }_{n+m} \mid \bar{C} .
$$

and

$$
\bar{C}=\bar{C}_{0: n}+e^{-\delta n} \int_{n}^{\infty} P(t) d t \bar{C}_{n: m}+{ }_{n+m} \mid \bar{C}
$$

where the first term is the expected present value of the cost for the emissions over the first $n$ years, the second term is the expected present value of the cost of $\mathrm{CO}_{2}$ emitted from time $n$ to time $n+m$, i.e. the deferred term cost, and the third term is the expected present value of the cost of $\mathrm{CO}_{2}$ emitted after time $n+m$.

Table 3 In this table, five-year term and five-year deferred costs are compared for different products

\begin{tabular}{lllll}
\hline $\begin{array}{l}\text { Wood product } \\
\text { usage }\end{array}$ & $\begin{array}{l}\text { Five-year term } \\
\text { cost, } \bar{C}_{0: 5}(\$)\end{array}$ & $\begin{array}{l}\text { Five-year } \\
\text { \% remaining }\end{array}$ & $\begin{array}{l}\text { Five-year deferred } \\
\text { cost, }{ }_{5} \mid \bar{C}(\$)\end{array}$ & $\begin{array}{l}\text { Total cost } \\
\bar{C}(\$)\end{array}$ \\
\hline Waste, bark, fuel & 23.74 & 48.95 & 18.04 & 41.78 \\
Pulpwood & 46.15 & 3.42 & 1.41 & 47.56 \\
Fencing & $1.001 \times 10^{-3}$ & 99.99 & 14.10 & 14.10 \\
\hline
\end{tabular}

We assume $1 \mathrm{t}$ of production (tons $\mathrm{CO}_{2}$ potential), an initial cost $b=\$ 50$ per ton $\mathrm{CO}_{2}$, an inflation rate in the cost of $\mathrm{CO}_{2}, r=2 \%$ and a long term continuous interest rate, $\delta=5 \%$ 


\section{Continued production}

In Marland et al. (2010) rather than using a single initial amount of wood stock, a model is constructed allowing continued production of wood stock given by a production function $J(t)$. Continuing the insurance analogy, this is comparable to a continuous amount of production of newborns to be insured by insurance agents. Below, we calculate the expected cost due to the production function $J(\cdot)$. Also, It is desirable to be able to track this cost using spreadsheet technology, hence the expression will be evaluated to a form consistent with this application.

The expected decay at time $u$ due to the production from time $\tau=0$ to $\tau=u$ is given by

$$
\int_{0}^{u} J(t-\tau) P(\tau) d \tau
$$

Assuming the cost per unit of $\mathrm{CO}_{2}$ at time $u$ is $b_{u}=b e^{r u}$, then the expected cost for the decay at time $u$ discounted back to $t=0$ is

$$
b e^{(r-\delta) u} \int_{0}^{u} J(u-\tau) P(\tau) d \tau
$$

Therefore, the total discounted expected cost due to the production $J(\cdot)$ is found by accumulating the costs continuously

$$
C_{J}=\int_{0}^{\infty} b e^{(r-\delta) u} \int_{0}^{u} J(u-\tau) P(\tau) d \tau d u
$$

Interchanging the order of integration we obtain

$$
C_{J}=\int_{0}^{\infty} \int_{\tau}^{\infty} b e^{(r-\delta) u} J(u-\tau) P(\tau) d u d \tau
$$

We change variables in the inner integral by defining $t=u-\tau$.

$$
C_{J}=\int_{0}^{\infty} \int_{0}^{\infty} b e^{(r-\delta)(t+\tau)} J(t) P(\tau) d t d \tau
$$

Finally,

$$
C_{J}=\int_{0}^{\infty} e^{(r-\delta) t} J(t) \int_{0}^{\infty} b e^{(r-\delta) \tau} P(\tau) d \tau d t
$$

Notice that the inner integral evaluates to $\bar{C}$ to obtain

$$
C_{J}=\int_{0}^{\infty} e^{(r-\delta) t} J(t) \bar{C} d t
$$

In Marland et al. (2010), the amount of decay due to continued production was discretized by assuming that production between anniversaries is constant. Using this method, we can rewrite $C_{J}$,

$$
\begin{aligned}
C_{J} & =\sum_{k=0}^{\infty} J(k) \int_{k}^{k+1} e^{(r-\delta) t} d t \bar{C} \\
& =\sum_{k=0}^{\infty} e^{-\delta k} J(k) \frac{1-e^{-(\delta-r)}}{\delta-r} e^{r k} \bar{C}
\end{aligned}
$$


Table 4 This table shows the distributional effect over a six year production period on the present value of the cost on three products

\begin{tabular}{llccc}
\hline Year & Production & Waste, bark, fuel $(\$)$ & Pulpwood $(\$)$ & Fencing (\$) \\
\hline 2010 & 12 & 493.92 & 562.27 & 166.67 \\
2011 & 15 & 617.40 & 702.83 & 208.34 \\
2012 & 19 & 782.04 & 890.26 & 263.89 \\
2013 & 22 & 905.52 & $1,030.82$ & 305.56 \\
2014 & 28 & $1,152.48$ & $1,311.96$ & 388.90 \\
2015 & 29 & $1,193.64$ & $1,358.81$ & 402.78 \\
PV total cost & & $4,397.50$ & $5,006.01$ & $1,483.90$ \\
\hline
\end{tabular}

We assume an initial cost of $b=\$ 50$ per ton $\mathrm{CO}_{2}$, an inflation rate in the cost of $\mathrm{CO}_{2}, r=2 \%$ and a long term continuous discount rate, $\delta=5 \%$

In the last expression, $\frac{1-e^{-(\delta-r)}}{\delta-r}$ is the value of a one year continuous annuity with force of interest $\delta-r$. The appearance of this term implies the cost $\bar{C}$ is being incurred continuously over the entire year corresponding to the year of production. This is the result of assuming $J(k)$ is contant over the course of the year. The expressions $J(k) \frac{1-e^{-(\delta-r)}}{\delta-r} e^{r k} \bar{C}, k=0,1, \ldots$ can now be used in a spreadsheet to calculate the expected present value of the cost due to the annualized production from the function $J(\cdot)$ (see Table 4).

We may also break each annual cost into its corresponding one year term costs by incorporating Eq. 6 into the expression. For a particular year of production $k$, we obtain the one-year term cost in year $k+n$

$$
J(k) \frac{1-e^{-(\delta-r)}}{\delta-r} e^{r k} \int_{n}^{\infty} P(t) \bar{C}_{n: 1} d t
$$

Example 5 Table 5 shows how this can be broken down for a fictitious production. To demonstrate the calculation for a value in Table 5, consider 2010 production in year 2012 for waste, bark, and fuel. From Example 3 we have calculated the third year term costs $\bar{C}_{2: 1}=7.20$ per ton $\mathrm{CO}_{2}$ potential with $\int_{2}^{\infty} P(t) d t=0.7889$ surviving oxidation to the end of year 2 . The continous one year annuity value with $\delta-r=0.03$ is $\frac{1-e^{-.03}}{0.03}=0.9851$. Taking the initial production in 2010 to be $J(0)=12$, we obtain $12 \times 0.9851 \times 0.7889 \times 7.20=\$ 67.15$.

Table 5 This table shows the one year term costs for multiple years of production for Waste, Bark, Fuel $(k=1.305, \theta=4.918)$

\begin{tabular}{lllcccc}
\hline Year & Production & $2010(\$)$ & $2011(\$)$ & $2012(\$)$ & $2013(\$)$ & $2014(\$)$ \\
\hline 2010 & 12 & 55.48 & 68.72 & 67.14 & 62.02 & 55.78 \\
2011 & 15 & & 70.75 & 87.64 & 85.63 & 79.09 \\
2012 & 19 & & & 91.42 & 113.25 & 110.65 \\
2013 & 22 & & & & 108.00 & 133.78 \\
2014 & 28 & & & & & 140.23 \\
2015 & 29 & & & & & \\
2016 & $\vdots$ & 55.48 & 139.47 & 246.21 & 368.90 & 519.54 \\
\hline
\end{tabular}

The initial cost of $\mathrm{CO}_{2}$ is $b=\$ 50$ per ton $\mathrm{CO}_{2}$, with an inflation rate of $2 \%$, and a long term discount rate of $5 \%$ 


\section{Value of the terminated contract}

This section covers the termination of a contract before the end of the term. It also covers the case where an obligation that is held by one party through some contract is sold to another party. It is important to accurately value the remaining portion of the contract.

In the case of paying a premium at the beginning of a term, the premium has not been technically earned until the life is exposed to a full term of hazards. With respect to the funding of the cost of emitting $\mathrm{CO}_{2}$ from oxidation, the party receiving the funding has not earned it until the term covered by the funding is completed. If the cost of the $\mathrm{CO}_{2}$ emission has been paid for in advance, then the term is not completed until the $\mathrm{CO}_{2}$ is emitted. When this prefunding takes place in a long term life insurance contract, in many cases the contract can be surrendered for the amount of prefunding not earned by the insurance company. This surrender value is sometimes called the cash value or non-forfeiture value. This option allows the insured who has been paying premiums for years and can no longer continue to pay, to recoup some of their premium that prefunded the contract. This would be to the disadvantage of the insurance company if it happened often in the early years, therefore insurance companies are allowed to recoup expenses by charging a surrender penalty against the surrender value early in the contract. In the case of purchasing carbon credits, a provision to surrender the contract and allow for further trading to take place with other parties may provide a more robust environment for a market to develop. Such provisions are well developed in the life insurance market and some of them may apply.

The most straightforward formulaic approach is to calculate the future liability that the contract has to the company and take this as a proxy for the contract value. This is normally stated as the present value of future benefits minus the present value of future premiums PVFB-PVFP (Lombardi 2006; Bowers et al. 1997, p. 206). Of course, these present values are really expected present values where the expectation is taken with respect to the underlying future lifetime distribution. In the context of the cost of $\mathrm{CO}_{2}$ emissions, the term PVFB is just the expected present value of the future cost of emissions covered by the contract. The term PVFP is the present value of future payments that the party providing the funding has yet to make on the contract. To illustrate this idea, with respect to trading in $\mathrm{CO}_{2}$ emissions, consider the following example.

Example 6 We bring together the previously calculated examples to demonstrate the use of the concept described in this section. Assume the cost of the contract is given by $\bar{C}$ for $1 \mathrm{t}$ (tons $\mathrm{CO}_{2}$ potential) of waste, bark, and fuel exposed to the hazard of oxidation January 1, 2010. The party funding the cost has agreed to pay five equal annual installments, $P$, beginning January 1, 2010. On December 31, 2011, the cost of the remaining tons $\mathrm{CO}_{2}$ potential is traded to a third party and the initial contract is terminated. The value of the terminated contract to the original funder is

$$
\left[\int_{2}^{\infty} P(t) d t\right] \int_{0}^{\infty}\left[b e^{r 2}\right] e^{(r-\delta)(\tau)} \frac{P(\tau+2)}{\int_{2}^{\infty} P(t) d t} d \tau-P \ddot{a}_{\overline{3 \mid}}
$$

To understand the formula, first consider the expression to the left of the minus sign. $\left[\int_{2}^{\infty} P(t) d t\right]$ is the amount of $\mathrm{CO}_{2}$ still sequestered from the original stock of 1 
$\mathrm{t}$ (tons $\mathrm{CO}_{2}$ potential), $\left[b e^{r 2}\right]$ is the cost of $\mathrm{CO}_{2}$ on December 31, 2011, and $\frac{P(\tau+2)}{\int_{2}^{\infty} P(t) d t}$ is the future lifetime distribution for the $\mathrm{CO}_{2}$ still sequestered. Hence the term to the left of the minus sign is the expected present value of the cost of the remaining carbon at the time December 31,2011. The term to the right of the minus sign is the present value of the three remaining payments, the first of which is due the next day. In Example 1 we calculated the net single cost of $1 \mathrm{t}$ of waste, bark and fuel to be $\$ 41.78$ under the assumptions described in the example. In Example 2, we calculated the the five year payout plan for this production to be $\bar{C} / \ddot{a}_{\overline{5 \mid}}=\$ 9.21$ using the same discount factor in $\ddot{a}_{\overline{5}}$ as was used in calculating $\bar{C}$. In Example 3 we calculated the amount of 1 $\mathrm{t}$ still remaining at time two years to be be $\int_{2}^{\infty} P(t) d t=0.7889 \mathrm{t}$.

In order to complete the trade, the termination value, i.e. amount of overpayment, needs to be calculated and returned to the original funder. Hence the value is given by

$$
\begin{gathered}
0.7889 \int_{0}^{\infty}\left[50 e^{.02 x 2}\right] e^{(-0.03) \tau} \frac{\operatorname{Gamma}(\tau+2)}{\int_{2}^{\infty} \operatorname{Gamma}(t) d t} d \tau-921.18 \ddot{a}_{\overline{3 \mid}} \\
=0.7889 \times 44.21-921.18 \times 2.856=\$ 8.57
\end{gathered}
$$

Therefore, the two payments of $\$ 9.21$ exceed the cost of the $\mathrm{CO}_{2}$ emitted at time two years by $\$ 8.57$. Hence, in this scenario, the party now responsible for the cost of $\mathrm{CO}_{2}$ still sequestered, will reimburse the original funder PVFB-PVFP $=\$ 8.57$ and agree to pay the remaining three payments which have value, PVFP, resulting in a net total cost of PVFB. Assuming this stock is still exposed to the same oxidation hazard as modeled initially and the cost function per ton and interest rate for discounting has not changed, the cost (as denoted PVFB in actuarial notation) is computed using the conditional distribution

$$
0.7889 \int_{0}^{\infty}\left[50 e^{.02 x 2}\right] e^{(-0.03) \tau} \frac{\operatorname{Gamma}(\tau+2)}{\int_{2}^{\infty} \operatorname{Gamma}(t) d t} d \tau=78.89 \times 44.21=\$ 34.88
$$

Otherwise, if a new long term force of interest, $\delta_{2}$, is agreed upon, as well as a new cost function, $b_{2, t}$, and the remaining stock is exposed to an oxidation hazard having a different oxidation distribution, $f_{T}(t)$, then the cost is calculated with respect to the new parameters, $0.7889 \bar{C}_{2}=0.7889 \int_{0}^{\infty} b_{2, t} e^{-\delta_{2} t} f_{T}(t) d t$ potentially resulting in an adjustment in the remaining payments.

\section{Error analysis and pricing}

In developing pricing structures for carbon release to the atmosphere, it is clear that there are some errors that need to be taken into account. The final payment from the emitter must include a term that we characterize here as the "risk charge" (Furman and Zitikis 2009).

$$
\text { Charge }=\text { Present Value }+ \text { Risk Charge }
$$

This risk charge, the difference between the actual payment and the net cost, reflects the cost in the variation of the estimations going into the present value calculations, that is, it reflects the downside cost for the risk of future results varying 
from what is expected. In the literature this additional cost is often referred to as the loading. In the insurance industry this is typically based on the variance of the distribution in the life tables and the variation in the estimates for the economic growth over the course of the coverage-insurance for the insurance, if you like. The more variance, the larger the risk charge. However, this loading may be based on other criteria, such as the probability that an event in the tail of the distribution will occur. For example, a product whose cost is sensitive to the path that interest rates take over time, may use a loading based on the expected value of the cost of the worst $10 \%$ of these interest rate paths. As insurance and financial products become more complex, the formulas used for this loading need to reflect the specific risks inherent in the products. This leads to the development of premium calculation principles (PCP). Three often quoted references for the development of PCP are Buhlmann (1970), Gerber (1979) and Goovaerts et al. (1984). For a more modern summary, presentation, and extension of these principles, as well as further references, see Furman and Zitikis (2009). In the case of carbon, there are three primary sources of error that will each contribute to the risk charge.

The first is the same as for the insurance industry, the error in economic forecasting. Predictions of the economic growth of the country or world in general determine the return on the investments that are made so that the costs can be paid. The farther out we want to make projections, the larger the variance will be. That is, economic forecasting is a bit like weather forecasting; making short term predictions is reasonably good, but the idea of following the numbers out for 100 years or more is, to put it mildly, likely to be a bit less reliable.

The second is the price of carbon release. Accurate estimates of this cost are elusive and making predictions farther out seems difficult. While the price of carbon release might be assumed to follow the basic economic rates after some initial transient fluctuations, scientific discoveries may create large, sudden changes in the price. Again, making long term predictions is problematic.

The final source of error is related to the release of the carbon into the atmosphere. We have made assumptions in this paper that we can fit particular products to probability distributions. If our fits are off by a few percentage points, how much error might there be in the resulting calculations for the present value of the released carbon?

To deal with the issue in general and to treat the particulars of the first two cases we will defer to a future paper. In the third case, we can make a few preliminary calculations to at least show how the errors propagate through the model. In a sense, this is a test of the robustness of the equations.

In the estimation of paramenters, $k$ and $\theta$, that describe the gamma probability distribution used here, we recognize the potential for error. The gamma parameters $\mathrm{k}$ and $\theta$ were obtained, in Marland et al. (2010), from data for the year of maximum decay and the $95 \%$ decay period for the carbon products listed in Table 2 . Since the parameters are likely to vary from the predicted value used in calculating the present value for a ton of $\mathrm{CO}_{2}$, the propagation of the error into the output of the present value calculation must be determined. This is accomplished here by adjusting the $\mathrm{k}$ and $\theta$ parameters by 1 and $10 \%$ and reworking the calculations. The extent of the propagation of the error between the two parameters is then listed in Table 6 below. The gamma distribution for each product with corresponding parameters was used to find the present value of each product at discount rates of 2 and $5 \%$ by Eq. 2 . 
Table 6 Errors in the expected value of the $\mathrm{CO}_{2}$ emissions assuming a 2 and $5 \%$ discount rate for several products

\begin{tabular}{|c|c|c|c|c|c|}
\hline \multirow{2}{*}{$\begin{array}{l}\text { Wood product } \\
\text { usage }\end{array}$} & \multicolumn{2}{|c|}{ Distr. parameters } & \multicolumn{3}{|c|}{ Present value of emissions } \\
\hline & $k$ & $\theta$ & Expected $(\$)$ & $1 \%$ error & $10 \%$ error \\
\hline \multicolumn{6}{|l|}{$2 \%$ discounting } \\
\hline Waste, bark, fuel & 1.305 & 4.918 & 44.24 & $\pm \$ 0.11$ & $\pm \$ 1.10$ \\
\hline Pulpwood & 1.418 & 1.196 & 48.35 & $\pm \$ 0.03$ & $\pm \$ 0.34$ \\
\hline Particleboard & 3.676 & 5.419 & 34.25 & $\pm \$ 0.26$ & $\pm \$ 2.54$ \\
\hline Pallet and packaging & 3.196 & 0.683 & 47.88 & $\pm \$ 0.04$ & $\pm \$ 0.43$ \\
\hline Fencing & 6.662 & 6.976 & 20.95 & $\pm \$ 0.36$ & $\pm \$ 3.65$ \\
\hline Construction & 6.740 & 25.045 & 2.96 & $\pm \$ 0.16$ & $\pm \$ 1.89$ \\
\hline Mining & 1.128 & 308.594 & 5.42 & $\pm \$ 0.17$ & $\pm \$ 1.99$ \\
\hline \multicolumn{6}{|l|}{$5 \%$ discounting } \\
\hline Waste, bark, fuel & 1.305 & 4.918 & 33.99 & $\pm \$ 3.74$ & $\pm \$ 5.55$ \\
\hline Pulpwood & 1.418 & 1.196 & 46.14 & $\pm \$ 0.17$ & $\pm \$ 0.87$ \\
\hline Particleboard & 3.676 & 5.419 & 20.71 & $\pm \$ 0.35$ & $\pm \$ 3.58$ \\
\hline Pallet and packaging & 3.196 & 0.683 & 44.91 & $\pm \$ 0.10$ & $\pm \$ 0.99$ \\
\hline Fencing & 6.662 & 6.976 & 6.81 & $\pm \$ 0.26$ & $\pm \$ 2.92$ \\
\hline Construction & 6.740 & 25.045 & 0.18 & $\pm \$ 0.02$ & $\pm \$ 0.14$ \\
\hline Mining & 1.128 & 308.594 & 2.13 & $\pm \$ 0.09$ & $\pm \$ 1.09$ \\
\hline
\end{tabular}

The error in the expected values reflect worst case scenarios for gamma distribution parameters $k$ and $\theta$ given errors in fitting the parameters based on product lifetimes in Marland et al. (2010). The last two columns represent estimated values of $k$ and $\theta 1$ and $10 \%$ off of the initial estimates

By changing values for $k$ and $\theta$ by combinations of \pm 1 and $\pm 10 \%$ for discount rates of 2 and $5 \%$, a maximum range was constructed for $1 \mathrm{t} \mathrm{CO}_{2}$, assuming $\$ 50$ per ton $\mathrm{CO}_{2}$. The combinations of changes in $k$ and $\theta$ that yielded the highest deviation from the original value were always found by simultaneously increasing or decreasing both parameters. The dollar values yielded by changing the parameters were subtracted from the starting dollar amount and the absolute value of the largest difference was used in reporting the range. This was done in order to provide the widest interval and most conservative error estimate.

The conclusion is that the longer lived products produce the largest errors. This is consistent with the difficulty in economic and carbon price forecasting in the two cases above. The longer the time over which errors might take place, the larger the total error will be.

After properly taking into account the potential sources of error and adding the risk charge, long term ("permanent") sequestration projects will include a much larger risk charge than short term projects. Shorter term contracts, even for long term storage, will include much smaller risk charges because the forecasting is more accurate.

\section{Discussion}

This paper is concerned with the cost of $\mathrm{CO}_{2}$ emissions as it relates to oxidation of products that contain carbon. It shows that the net present value of the cost of emissions depends on when the emissions actually occur and that it behooves us to 
accurately characterize the time of emissions. The payment for emissions will depend not only on when the emissions occur but on when and how the payment is made.

As a consequence of framing the oxidation of carbon containing products as probability distributions, we gain access to the theory developed for the life insurance industry and the methods used to develop that theory. The analogy allows us to develop some insightful theory on the pricing of carbon release based on the pricing structures that exist in the life insurance industry. The theories developed here outline in a very general way the basic approach that can be applied to contractual products in this new venue. In particular, a whole life model is used to develop a net single cost for $\mathrm{CO}_{2}$ emisions. Other insurance models are used to mitigate some of the disadvantages of using the net single cost. The term cost model allows short term assumptions and a revisiting of the cost calculation over a shorter time horizon. The shorter time horizon allows more accurate economic, technological, and scientific projections. Term and deferred cost models allow a contract to be split among multiple parties. Finally, the actuarial principle underlying the calculation of a policy reserve, gives rise to a method of placing a value on a contract between its initiation and maturity. This creates a theory by which existing contracts can be renegotiated or traded.

In addition, the theory developed here, with respect to the value of a distributional oxidation of a carbon containing product, is not limited to durable wood products but would apply similarly to fossil fuel products such as lubricants, waxes, and synthetic fibers. Although we have tended to use gamma distributions in our examples, any probability distribution that represents the oxidation or removal of the product from service will suffice. The distribution may be strongly right skewed with most of the oxidation taking place very shortly after production. Part of the value of the approach in this paper is the generality.

Our focus here has been on the mathematics and not on policy. Reflecting on the possible implementation of these ideas, it is clear that there are some difficulties that still need to be worked out, by both economists and policy makers. There are also some interesting questions that become accessible once we begin moving down the path we have opened. Some of the challenges relate to the economic policies and others are more related to the proper accounting of the flow of carbon.

One of the major concerns that quickly arises is how to deal with extremely long lived products or with strategies that attempt to permanently sequester carbon. Because the expected lifetimes of those products and strategies are extremely long, small errors can make significant differences. How do you deal with a sequestration strategy that is "permanent"? How do you deal with products that might require extremely long contracts-perhaps longer than the lifetime of the party itself? Is it reasonable to talk about arrangements with parties that extend one hundred or more years into the future?

Finally, now that we see the importance of the time release of carbon, we recognize that there are spatial and ownership differences as well. What are the effects of the physical separation that exists between sequestration projects and emissions? To what extent can the sequestration and emission be averaged or are there additional influences due to the separation? In fact the current political discussion of durable wood products (see for example, IPCC 2007; Marland et al. 2010) is focussed on the distribution of credits and costs among those who own the forest and those who use or hold the wood products. Our discussion is premised on the idea that 
those who hold the wood products are responsible when those products oxidize but the principles developed are equally appropriate for the other approaches under consideration.

\section{References}

Bowers NL et al (1997) Actuarial mathematics, 2nd edn. The Society of Actuaries, Schaumburg

Buhlmann H (1970) Mathematical methods in risk theory. Springer, Berlin

Cunningham R, Herzog T, London R (2008) Models for quantifying risk, 3rd edn. Actex Publications, Winsted

Federal Agency Working Group (2010) Appendix 15A: Social cost of carbon for regulatory impact analysis under executive order 12866. Available online at http://www2.eere.energy.gov/ buildings/appliance_standards/commercial/pdfs/sem_finalrule_appendix15a

Furman E, Zitikis R (2009) Weighted pricing functionals with applications to insurance: an overview. N Am Actuar J 13(4):483-496

Gerber HU (1979) An introduction to mathematical risk theory. University of Pennsylvania Press, Philadelphia

Goovaerts MJ, de Vylder F, Haezendonck J (1984) Insurance premiums: theory and applications. North-Holland, Amsterdam

IPCC (1997) In: Houghton JT, Meira Filho LG, Lim B, Treanton K, Mamaty I, Bonduki Y, Griggs DJ, Callandar BA (eds) Revised 1996 IPCC guidelines for national greenhouse gas inventories. Intergovernmental Panel on Climate Change

IPCC (2007) 2006 IPCC guidelines for national greenhouse gas inventories. Intergovernmental Panel on Climate Change

Lombardi LJ (2006) Valuation of life insurance liabilities, 4th edn. Actex Publications, Winsted, pp 1-2

Marland E, Marland G (2003) The treatment of long-lived, carbon containing products in inventories of carbon dioxide emissions to the atmosphere. Environ Sci Policy 6(2):139-152

Marland ES, Stellar K, Marland GH (2010) A distributed approach to accounting for carbon in wood products. Mitig Adapt Strateg Glob Change 15:71-91

National Research Council (2010) Verifying greenhouse gas emissions: methods to support international climate agreements. US National Research Council of the National Academies, The National Academies Press, Washington DC

Pingoud K, Perälä A-L, Soimakallio S, Pussinen A (2003) Greenhouse gas impacts of harvested wood products: evaluation and development of methods. VTT Research Notes 2189, VTT, Espoo, Finland

Stern N (2007) The economics of climate change; the Stern report. Cambridge University Press, Cambridge, $712 \mathrm{pp}$ 